\title{
Inhibition of multidrug resistance protein 1 (MRP1) improves chemotherapy drug response in primary and recurrent glioblastoma multiforme
}

\author{
Amanda Tivnan ${ }^{1 *}$, Zaitun Zakaria ${ }^{1}$, Caitrín O'Leary ${ }^{1}$, Donat Kögel ${ }^{2}$, Jenny L. Pokorny ${ }^{3}$, \\ Jann N. Sarkaria ${ }^{3}$ and Jochen H. M. Prehn ${ }^{1}$ \\ ${ }^{1}$ Department of Physiology and Medical Physics, Centre for Systems Medicine, Royal College of Surgeons in Ireland, Dublin, \\ Ireland, ${ }^{2}$ Experimental Neurosurgery, Neuroscience Center, Frankfurt University Hospital, Frankfurt am Main, Germany, \\ ${ }^{3}$ Department of Radiation Oncology, Mayo Clinic, Rochester, MN, USA
}

\section{OPEN ACCESS}

Edited by:

Ashok Kumar,

University of Florida, USA

Reviewed by:

Karthik Bodhinathan,

Sanford Burnham Medical Research

Institute, USA

Venkata Subba Rao Atluri,

Florida International University, USA

*Correspondence: Amanda Tivnan,

Department of Physiology and Medical Physics, Centre for Systems Medicine, Royal College of Surgeons in Ireland, York House, St. Stephens

Green, Dublin 2, Ireland amandativnan@rcsi.ie

Specialty section This article was submitted to Neuropharmacology, a section of the journal Frontiers in Neuroscience

Received: 29 April 2015 Accepted: 31 May 2015

Published: 16 June 2015

Citation:

Tivnan A, Zakaria Z, O'Leary C, Kögel D, Pokorny JL, Sarkaria JN and Prehn JHM (2015) Inhibition of multidrug resistance protein 1 (MRP1) improves chemotherapy drug response in primary and recurrent glioblastoma multiforme. Front. Neurosci. 9:218. doi: 10.3389/fnins.2015.00218
Glioblastoma multiforme (GBM) is a highly aggressive brain cancer with extremely poor prognostic outcome despite intensive treatment. All chemotherapeutic agents currently used have no greater than 30-40\% response rate, many fall into the range of $10-20 \%$, with delivery across the blood brain barrier (BBB) or chemoresistance contributing to the extremely poor outcomes despite treatment. Increased expression of the multidrug resistance protein 1(MRP1) in high grade glioma, and it's role in BBB active transport, highlights this member of the $\mathrm{ABC}$ transporter family as a target for improving drug responses in GBM. In this study we show that small molecule inhibitors and gene silencing of MRP1 had a significant effect on GBM cell response to temozolomide $(150 \mu \mathrm{M})$, vincristine $(100 \mathrm{nM})$, and etoposide $(2 \mu \mathrm{M})$. Pre-treatment with Reversan (inhibitor of MRP1 and P-glycoprotein) led to a significantly improved response to cell death in the presence of all three chemotherapeutics, in both primary and recurrent GBM cells. The presence of MK571 (inhibitor of MRP1 and multidrug resistance protein 4 (MRP4) led to an enhanced effect of vincristine and etoposide in reducing cell viability over a $72 \mathrm{~h}$ period. Specific MRP1 inhibition led to a significant increase in vincristine and etoposide-induced cell death in all three cell lines assessed. Treatment with MK571, or specific MRP1 knockdown, did not have any effect on temozolomide drug response in these cells. These findings have significant implications in providing researchers an opportunity to improve currently used chemotherapeutics for the initial treatment of primary GBM, and improved treatment for recurrent GBM patients.

Keywords: glioblastoma, multidrug resistance protein 1, siRNA, chemoresistance

\section{Introduction}

Glioblastoma multiforme (GBM) is a highly aggressive grade IV brain cancer with an extremely poor prognostic outcome despite intensive treatment regimes. GBM represent approximately $17 \%$ of all primary brain tumors diagnosed worldwide; and $60-75 \%$ of astrocytomas, increasing in frequency with age (WHO and IARC, 2008). Prognosis is reported as "median survival" which, 
for adults with aggressive GBM treated according to the standard Stupp protocol (Stupp et al., 2005) is 14.6 months. The average five year survival is less than $3 \%$, leading to the fact that GBM is the most lethal form of brain tumor.

The standard clinical treatment of newly diagnosed GBM is known as the Stupp protocol, outlined in 2005 (Stupp et al., 2005) as radiotherapy (fractionated focal irradiation in daily fractions of 2 Gy given for 5 days per week for 6 weeks for a total of 60 Gy) in combination with daily temozolomide (TMZ) $\left(75 \mathrm{mg} / \mathrm{m}^{2}\right.$ body surface area) administered continuously. Such protocols increased median survival rates in GBM patients from 12.1 months with RT alone to 14.6 months for TMZ/RT treatment.

Despite surgical resection of GBM tumors, recurrence at distal sites is typically 6.9 months (Stupp et al., 2005, 2009, 2010) and in instances where repeat resection is not a viable option, adjunct chemotherapy is ineffective at stopping tumor progression and eventually, morbidity. Chemotherapy used for recurrent GBM includes the PCV regime [procarbazine, CCNU (lomustine), and vincristine] (Brada et al., 2010) and/or the ACE regime (bevacizumab combined with carboplatin and etoposide); both of which are used as palliative therapy in recurrent GBM. All agents used; however, have no greater than $30-40 \%$ response rate and many fall into the range of 10-20\%(Bota et al., 2007) with delivery or chemoresistance contributing to the extremely poor patient outcomes despite treatment.

A major hindrance to several chemotherapeutic agents in effective GBM treatment is their efficient transport across the blood brain barrier (BBB). For this reason, several researchers have focused their studies on novel mechanisms of drug delivery across the $\mathrm{BBB}$ and distribution throughout the brain (Campbell et al., 2008). The role of the BBB in brain homeostasis is maintained through the action of active efflux transporters of the ATP-binding cassette (ABC) family including p-glycoprotein (Pgp), the multidrug resistance proteins (MRPs), and breast cancer resistance protein (BCRP) (Loscher and Potschka, 2005a,b,c). The significant role which MRPs play in chemoresistant GBM patients was identified in 1995 by Abe et al. (1994) with high grade gliomas (HGGs) showing a significant increase in expression of several MRPs including MRP1 (ABCC1). However, it was the localized expression of MRP1 within GBM tumor specimens themselves in addition to the tumor vasculature, identified by Calatozzolo et al. (2005) which was of particular interest to the authors. As such, this paper outlines the role of MRP1 inhibition in improving chemotherapy drug response in both primary and recurrent GBM patient-biopsy derived cell lines; as evaluated in vitro, suggesting an intrinsic chemoresistance role of MRP1 expression in GBM tumor cells, independent of the $\mathrm{B}-\mathrm{BB}$ endothelial transport system. In this regard, it may be suggested that increased MRP1 expression in high grade gliomas, such as glioblastoma multiforme, contribute to chemoresistance through increased drug efflux and reduced bioavailability of the administered chemotherapeutic within the cancerous cell. Improving intracellular exposure to efficient chemotherapeutics, through MRP1 targeted reduction, would significantly increase GBM cell death when used in combination with chemotherapeutic agents.

\section{Materials and Methods}

\section{Cell Culture and siRNA Transfections}

Commercially available glioblastoma cell lines U251 and A172 (ECACC), glioblastoma cell lines derived from primary tumors, MZ-327 and MZ-18 and glioblastoma cell lines derived from recurrent grade IV tumors, MZ-256 and MZ-304 (Hetschko et al., 2008), were grown as a monolayer in DMEM with $10 \%$ heatinactivated fetal calf serum, $100 \mathrm{U} / \mathrm{ml}$ penicillin, and $100 \mathrm{mg} / \mathrm{ml}$ streptomycin and maintained in a humidified incubator at $37^{\circ} \mathrm{C}$ and $5 \% \mathrm{CO}_{2}$. For siRNA transfections, cells were seeded at $7 \times$ $10^{5}$ cells in a T25 flask (GIBCO) and maintained at $37^{\circ} \mathrm{C}$ and $5 \% \mathrm{CO}_{2}$ for $24 \mathrm{~h}$. Media was then removed from all flasks in the dark, and replaced with $5 \mathrm{ml}$ of OptiMem media (GIBCO, UK). Cells were transiently transfected with either MRP1-specific siRNA (GATGACACCTCTCAACAAAdTdT $30 \mathrm{nM}$ ) or a nontargeting negative control siRNA (30 nM, ON-TARGET plus Non-targeting siRNA\#1, Dharmacon, US), using Lipofectamine 2000 (Invitrogen, US) according to manufacturer's protocol. All flasks were incubated at $37^{\circ} \mathrm{C}$ and $5 \% \mathrm{CO} 2$ for $96 \mathrm{~h}$.

\section{Protein Extraction and Western Blot Analysis}

Transfected cells were washed with phosphate buffered saline (PBS), trypsinised and cells were centrifuged at $1000 \mathrm{rpm}$ for $3 \mathrm{~min}$. The supernatant was then removed and protein was extracted from cells by resuspending the resulting pellet in RIPA buffer (50 mM Tris $\mathrm{pH} 7.4,150 \mathrm{mM} \mathrm{NaCl}, 0.2 \% \mathrm{NP}-40$, $50 \mathrm{mM} \mathrm{NaF}, 5 \mathrm{mM}$ EDTA, $0.1 \mathrm{mM}$ orthovanadate, plus protease inhibitor cocktail SIGMA [P8340]). Resuspended cells in RIPA were left on ice for $15 \mathrm{~min}$ before centrifugation at $4^{\circ} \mathrm{C}$ and $16,000 \mathrm{rpm}$ for $15 \mathrm{~min}$. Protein supernatant was taken from each sample, quantified and stored at $-20^{\circ} \mathrm{C}$. Patient-derived primary glioblastoma (G6, G8, G12, G38, G39, G43, G44, G59, and G75), recurrent glioblastoma (G14, G46, G64, and G76), Oligoastrocytoma (G10), and Gliosarcoma (G22 and G28) lysates were provided by Mayo Clinic Brain Tumor SPORE (Giannini et al., 2005; Sarkaria et al., 2006, 2007, 2008).

\section{Western Blotting}

Western blot analysis was performed on lysates prepared as outlined previously. Western blots were carried out using 4$10 \%$ gradient pre-cast gels and HEPES running buffer (PIERCE). Protein samples were mixed with $10 \mu \mathrm{l}$ of $1 \mathrm{xDTT}$ loading buffer (6x buffer: 4x Tris.Cl/SDS pH6.8, Glycerol 30\%, SDS $10 \%$, DTT 0.6 M, Bromophenol Blue 0.012\%) and loaded into gels. Gels were run at $100 \mathrm{~V}$ for $45 \mathrm{~min}$ and transferred onto nitrocellulose membranes at $45 \mathrm{~V}$ for $90 \mathrm{~min}$, using wet transfer buffer [10x Transfer buffer $(100 \mathrm{ml})$, Methanol $(200 \mathrm{ml})$, sterile water $(700 \mathrm{ml})$ ] [10xTranfers buffer: Tris $(30.3 \mathrm{~g})$, glycine (144 g) Sterile $\left.\mathrm{H}_{2} \mathrm{O}(1000 \mathrm{ml})\right]$. Membranes were then blocked in $10 \%$ milk-TBST overnight at $4^{\circ} \mathrm{C}$. Membranes were incubated with primary anti-MRP1 antibody (Enzo Life Sciences ALX-801-007C125; $1: 500)$ in TBST-milk (0.5\%) for $2 \mathrm{~h}$ at room temperature. Membranes were then washed three times with TBST for $5 \mathrm{~min}$ and secondary anti-rat HRP conjugated antibody (Abcam, 1:5000) was then added for a further $2 \mathrm{~h}$. Loading control protein beta actin was assessed by incubation of the membrane with 
anti-beta actin antibody (Abcam, 1:5000) in TBST for $1 \mathrm{~h}$ at room temperature. Membranes were then washed in TBST three times for $5 \mathrm{~min}$ each, after which a secondary anti-mouse HRP conjugated antibody (Sigma, 1:5000) was added for $1 \mathrm{~h}$, followed by further washes with TBST $(3 \times 5 \mathrm{~min})$. All segments were then developed and the images assessed on a LAS Imager 3000. Densitometry analysis of protein bands was analyzed using ImageJ, MRP1 protein bands were normalized to B-actin loading controls and unpaired Student $T$-tests were carried out where appropriate.

\section{Drug Treatment and Metylthiazol Tetrazolium Assay (MTT) Assay}

Glioblastoma cell lines were seeded into a 96 well plate either directly, or $6 \mathrm{~h}$ post transfection with an MRP1-targeting or a non-targeting negative control siRNA. Cells were seeded onto 96 well plates at a concentration of $1 \times 10^{3}$ cells per well and incubated for $72 \mathrm{~h}$ at $37^{\circ} \mathrm{C}$ and $5 \% \mathrm{CO} 2$ to allow MRP1 messenger RNA suppression to occur. Cells were then treated with either control media or one of three chemotherapy drugs temozolomide $(150 \mu \mathrm{M})$, vincristine $(100 \mathrm{nM})$, or etoposide $(2 \mu \mathrm{M})$ (generously provided by Dr. Markus Rehm). Cells were then returned to the incubator for a further $72 \mathrm{~h}$; after which time, Metylthiazol Tetrazolium (MTT) powder in PBS $(50 \mu \mathrm{l}$ of $5 \mathrm{mg} / \mathrm{ml})$ was added to each well. Cells were then incubated for a further $4 \mathrm{~h}$ after which all solution was removed and dimethyl sulfoxide (DMSO) was added. After $10 \mathrm{~min}$ incubation time at $37^{\circ} \mathrm{C}$, absorbance was recorded at $570 \mathrm{~nm}$ wavelength and data was recorded and analyzed. Small molecule inhibitors MK571 (25 $\mu \mathrm{M})$ and Reversan $(15 \mu \mathrm{M})$ were added $7 \mathrm{~h}$ prior to carrying out further drug treatment (temozolomide, vincristine or etoposide) or assay assessment (media change for proliferation and 2D-migration assays).

\section{Cell Proliferation Assay}

Glioblastoma cells U251, MZ-256, and MZ-327 were pretreated with the MRP1 small molecule inhibitor MK571 (M7571 SIGMA) and Reversan (SML0173 SIGMA) at a final concentration of 25 and $15 \mu \mathrm{M}$; respectively, for $7 \mathrm{~h}$ and subsequently were seeded at $1 \times 10^{4}$ cells/well in a 6 well plate and allowed to adhere overnight. Cells were then allowed to grow for $96 \mathrm{~h}$ and counted using the trypan blue exclusion method.

\section{Cell Migration Assay}

Glioblastoma cells U251, MZ-256, and MZ-327 were pretreated with the MRP1 small molecule inhibitor Reversan (SML0173 SIGMA) at a final concentration of $15 \mu \mathrm{M}$ for $7 \mathrm{~h}$ and subsequently seeded at $5 \times 10^{4}$ cells into wound chambers (Ibidi, US, Cat\#80206) and allowed to adhere overnight. The wound assay insert was removed, the initial wound was photographed, cells were allowed to grow for 19-24h, dependent on cell type, and then wound closure was re-photographed and assessed

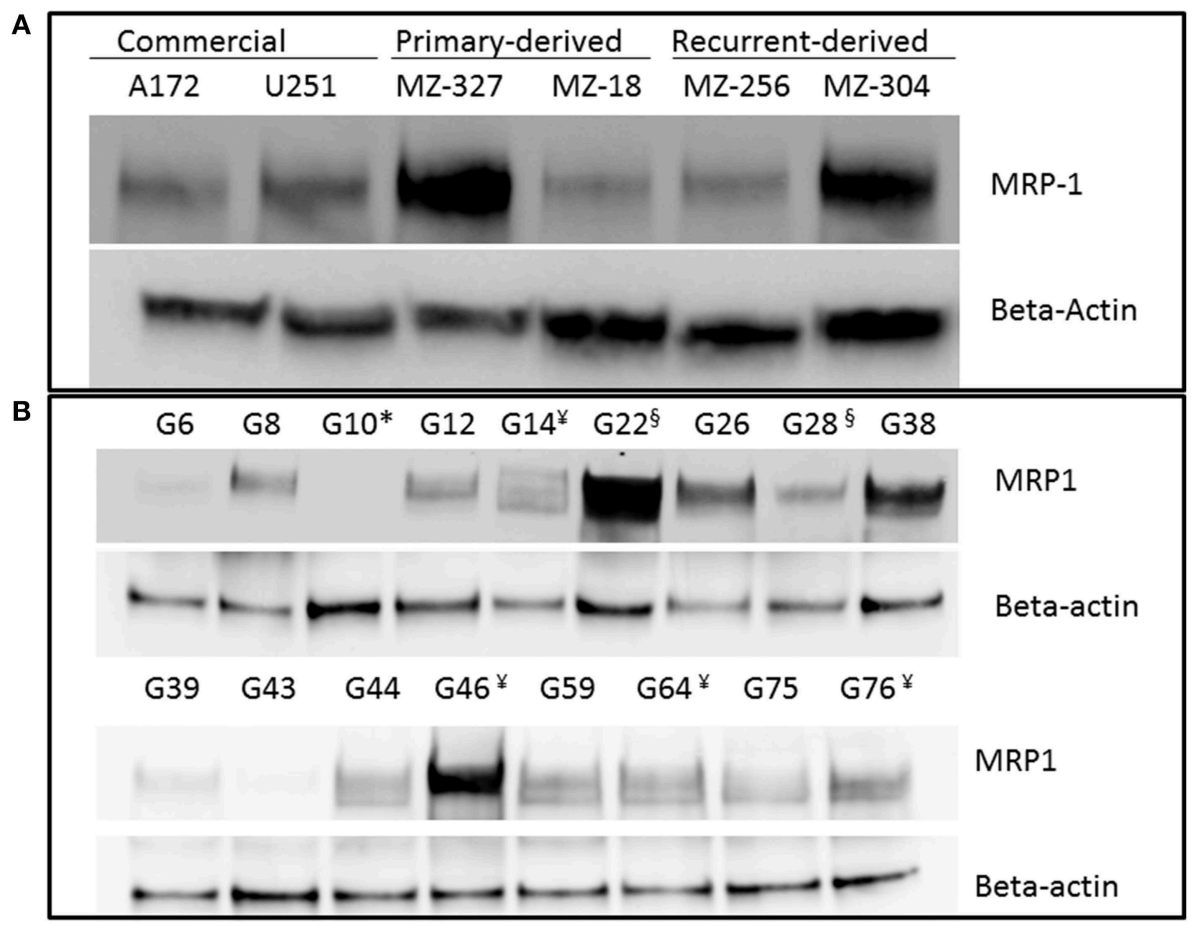

FIGURE 1 | Western Blot of MRP1 expression in commercial, primary, and recurrent GBM cell lines. Western blot analysis was performed on lysates prepared from A172, U251, MZ-327, MZ-18, MZ-256 and MZ-304 glioblastoma cell lines (A) Additionally, patient-derived primary glioblastoma (G6, G8, G12, G38, G39, G43,
G44, G59, and G75), recurrent glioblastoma ${ }^{¥}$ (G14, G46, G64, and G76), Oligoastrocytoma* (G10), and Gliosarcoma ${ }^{\S}$ (G22 and G28) lysates were assessed for MRP1 expression (B) Developed membranes showed MRP1 expression at $190 \mathrm{kDa}$ in varying amounts across the cell lines assessed. 
using WimScratch Quantitative Wound Healing Image Analysis (Ibidi, USA).

\section{Results}

\section{GBM Cell Lines Drug Response after Small Molecule Inhibition of MRP1 using MK571 and Reversan}

A variety of glioblastoma multiforme cell lines were chosen for this study based upon their origins and available clinical data. Commercially available GBM cell lines A172 and U251, cell lines derived from primary GBM tumor biopsies (designated MZ-327 and MZ-18), along with cells established from a recurrent tumor biopsy (MZ-256 and MZ-304) (Hetschko et al., 2008; Murphy et al., 2014) were used in assessing the effects of pre-treating GBM cells with MRP1 small molecule inhibitors. All cell lines were assessed in terms of their MRP1 protein expression when grown as a monolayer in DMEM media (Figure 1A). Additionally, patient-derived primary glioblastoma (G6, G8, G12, G38, G39, G43, G44, G59, and G75), recurrent glioblastoma (G14, G46, G64, and G76), Oligoastrocytoma (G10), and Gliosarcoma (G22 and G28) lysates were assessed with respect to their MRP1 expression (Figure 1B). To allow analysis across various cell lines, densitometry analysis of protein bands was carried out using ImageJ, MRP1 protein bands were normalized to B-actin loading controls (Supplementary Figures $1 \mathrm{~A}, \mathrm{~B}$ ). In terms of in vitro assessment, A172, U251, MZ-327, MZ-18, MZ-256, and MZ-304 were used for evaluation of MRP1 inhibition and chemotherapy response. Addition of small molecule inhibitors of MRP1 had a significant effect on GBM cell drug responses to temozolomide, vincristine, and etoposide. Notably, MK571 is a non-specific inhibitor of MRP1, also known to act on MRP4 (Reid et al., 2003); while Reversan not only inhibits MRP1, but also P-glycoprotein (Pgp) very effectively (Burkhart et al., 2009; Henderson et al., 2011). As shown in Figure 2A, inhibition of MRP1 and MRP4 by MK571 did not lead to a profound change in drug-induced cell death in any of the commercial cell lines assessed. Pre-treatment

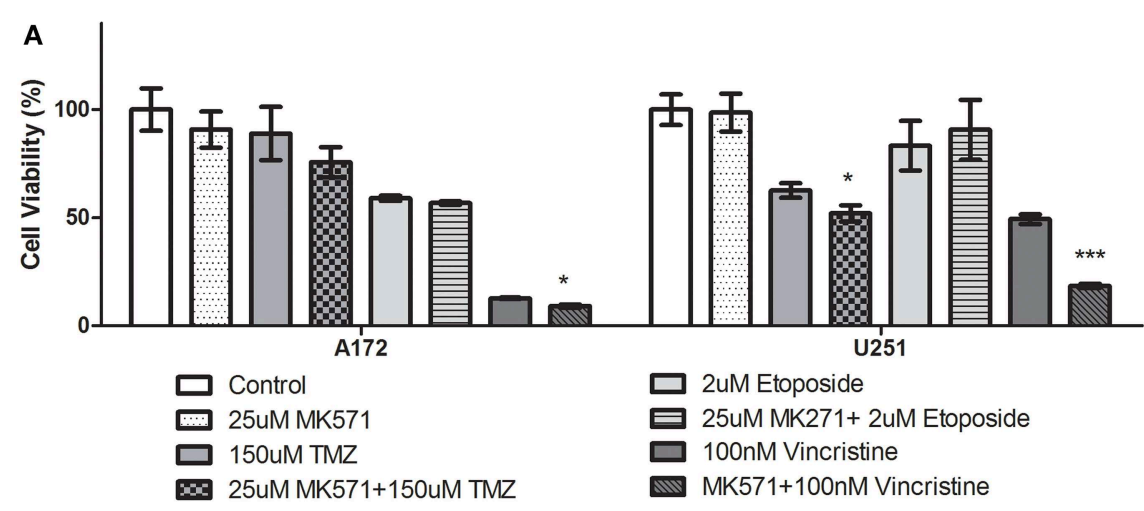

B

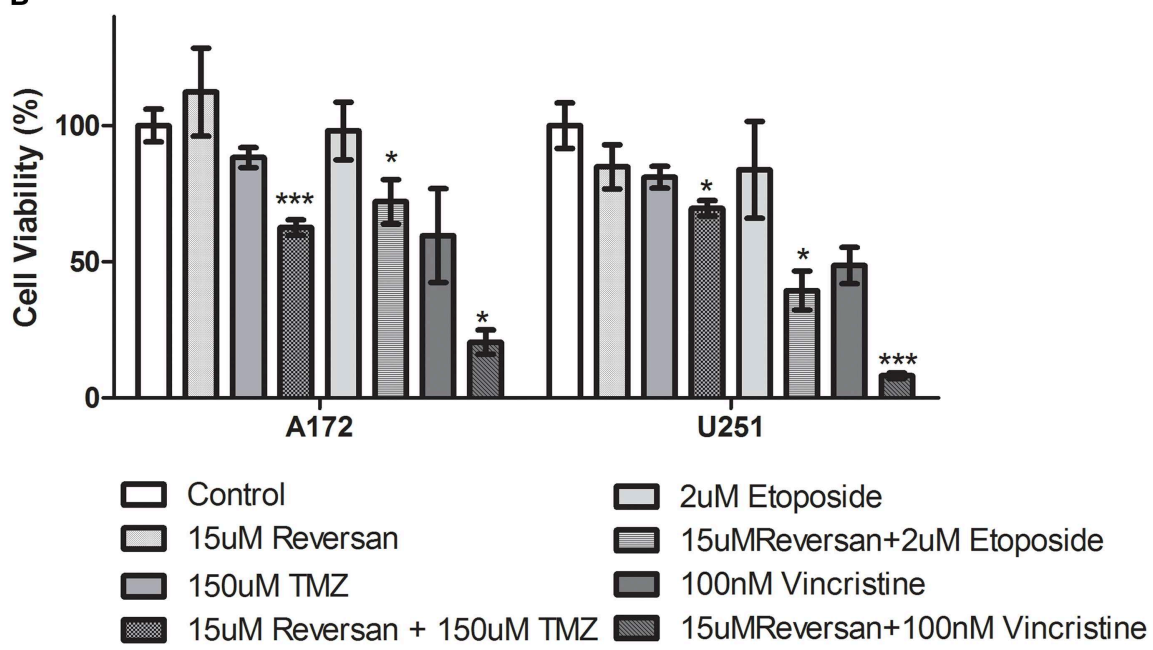

FIGURE 2 | Small Molecule inhibition of MRP1 and chemoresponse in GBM Commercial cell lines. (A) The effects of MK571 on temozolomide, vincristine or etoposide-induced cell death in commercial GBM lines is negligible. MK571 enhanced vincristine-induced cell death $\left({ }^{*} p<0.05\right)$ in A172 cells while treatment of U251 cells with the small molecule MRP1 inhibitor leads to enhanced temozolomide and vincristine-induced cell death relative to chemotherapy alone treatment $\left({ }^{*} p<0.05\right)$. Treatment of $A 172$ and U251 with Reversan $(15 \mu \mathrm{M})$ leads to a significant increase in temozolomide, vincristine, and etoposide-induced cell death compared to chemotherapy drug treatment alone (B) $\left(n=3{ }^{*} p<0.05\right.$, ${ }^{* * *} p<0.001$, Unpaired Student $T$-test). 
with Reversan however, which would inhibit MRP1 and Pgp, led to an improved response in terms of temozolomide, vincristine and etoposide-induced cell death, Figure 2B. The most notably enhanced cell death was evident in both A172 and U251 cells treated with a combination of Reversan and vincristine $(100 \mathrm{~nm})$. In the case of primary (MZ-327 and MZ-18, Figure 3A) and recurrent (MZ-256 and MZ-304, Figure 4A) GBM tumor biopsy derived cell lines; in both cases the presence of MK571 led to an enhanced effect of vincristine and etoposide in reducing cell viability over a $72 \mathrm{~h}$ period. MRP1 and MRP4 inhibition by MK571 did not have any effect on temozolomide drug response in these cells. Reversan-mediated inhibition of MRP1 and Pgp led to significant enhancement of temozolomide, vincristine and etoposide-induced cell death in primary (Figure 3B) and recurrent (Figure 4B) GBM cell lines.

\section{Specific Inhibition of MRP1 Using Short-interfering (si)RNA and Drug Response Assessment}

As mentioned previously, due to the non-specific nature of the small molecule inhibitors currently available to assess MRP1 inhibition in vitro, siRNA were designed which specifically target MRP1 mRNA; hereby inhibiting protein expression. As shown in Figure 5A, transient transfection of U251, MZ-18, and MZ-256 cells led to reduced MRP1 expression after $96 \mathrm{~h}$. Notably, as shown in lanes 3, 4, 5, and 6 of Figure 5A; MRP1 expression post-transfection is optimal at $96 \mathrm{~h}$, with a noted re-expression of the target protein by $120 \mathrm{~h}$. This was confirmed using densitometry analysis of MRP1 protein bands, analyzed using ImageJ, where MRP1 protein was normalized to B-actin loading controls and unpaired Student $T$-tests were carried

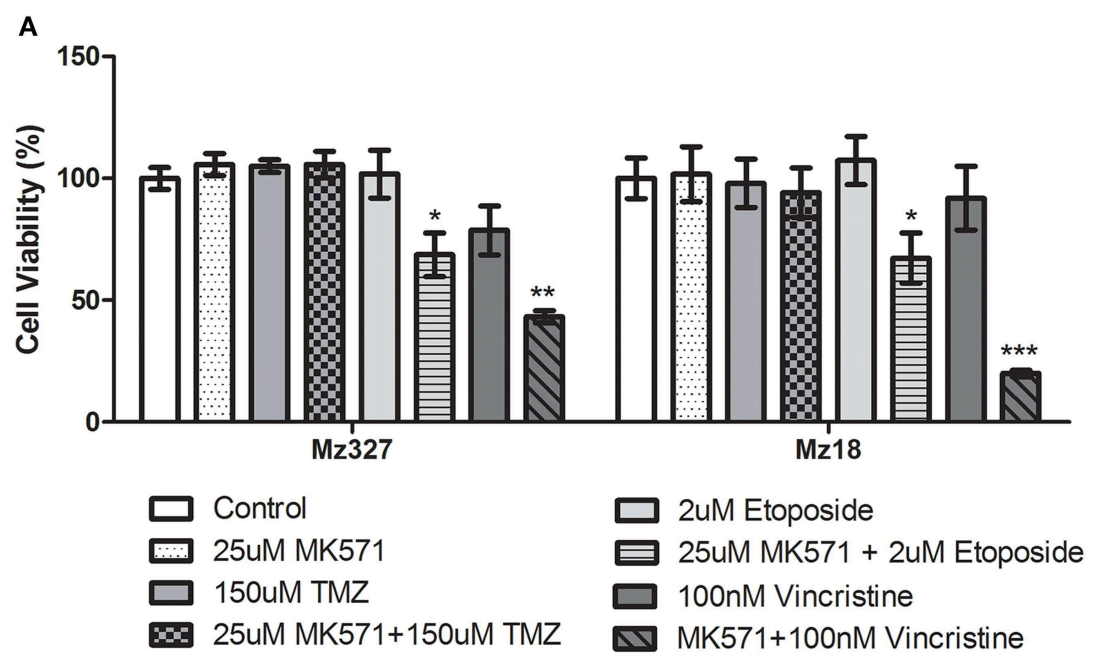

B

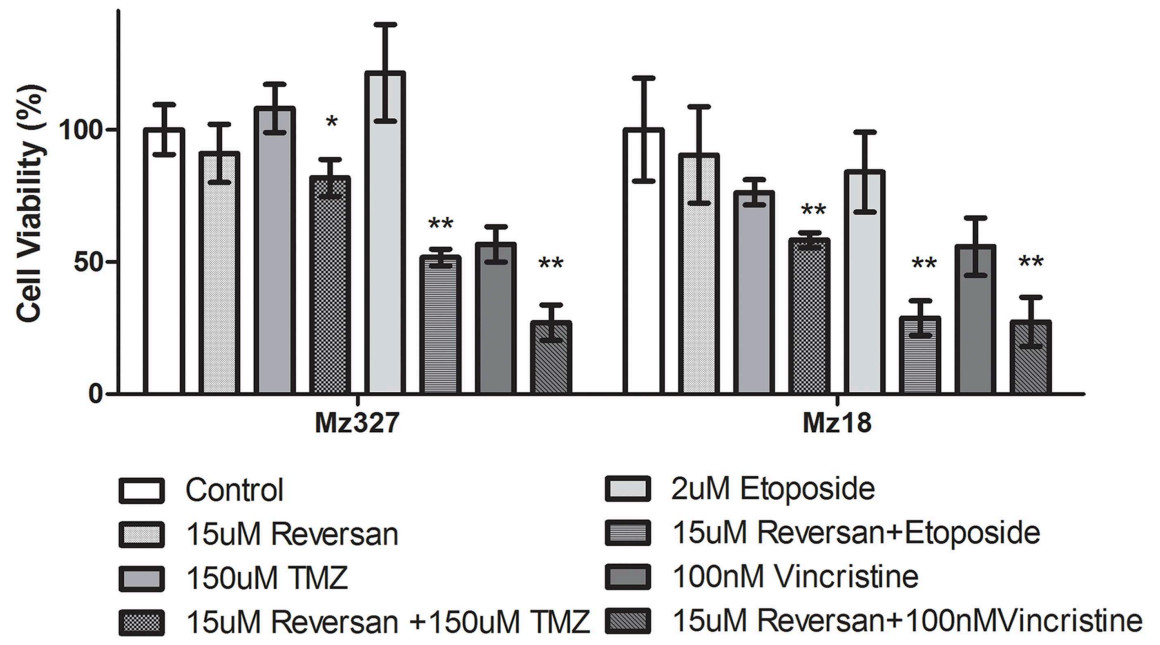

FIGURE 3 | Small Molecule inhibition of MRP1 and chemoresponse in Primary GBM tumor derived cell lines. (A) Treatment of primary tumor-derived GBM cell lines, MZ-327, and MZ-18, led to a significant increase in both vincristine and etoposide-induced cell death compared to chemotherapy treatment alone $\left(n=3{ }^{*} p<0.05,{ }^{* *} p<0.01,{ }^{* \star *} p<0.001\right.$
Unpaired Student $T$-test). The presence of MK571 (25 $\mu \mathrm{M})$ did not have any effect on temozolomide-induced cell death in either of these cell lines. Treatment with Reversan $(15 \mu \mathrm{M})$ significantly increased cell death for all three chemotherapies tested $\left(n=3{ }^{*} p<0.05,{ }^{*} p<0.01\right.$ Unpaired Student $T$-test) in both lines assessed (B) relative to single chemotherapy drug treatment. 

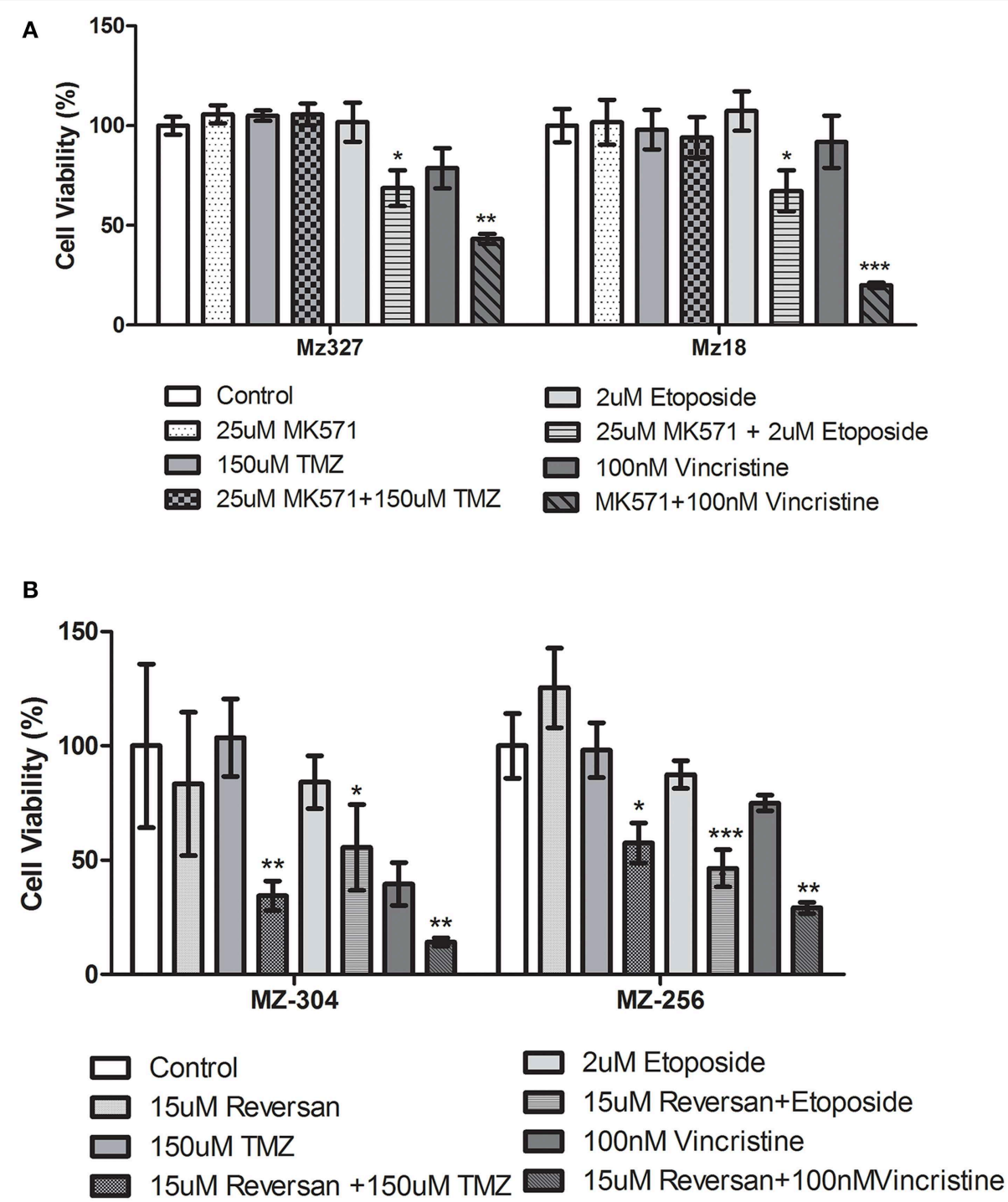

FIGURE 4 | Small molecule inhibition of MRP1 and chemoresponse in Recurrent GBM tumor derived cell lines. Treatment of recurrent tumor-derived GBM cell lines, MZ-304, and MZ-256, led to a significant increase in both vincristine and etoposide-induced cell death $(n=3$ ${ }^{\star} p<0.05,{ }^{* *} p<0.01,{ }^{\star * *} p<0.001$ Unpaired Student $T$-test) (A) compared to chemotherapy alone treatment. The presence of MK571 (25 $\mu \mathrm{M})$ did not have any effect on temozolomide-induced cell death in either of these cell lines. Treatment with Reversan $(15 \mu \mathrm{M})$, significantly increased cell death for all three chemotherapies tested $\left(n=3{ }^{*} p<0.05,{ }^{* *} p<0.01,{ }^{* * *} p<0.001\right.$ Unpaired Student $T$-test) in both lines assessed (B). out to verify target suppression relative to negative control siRNA treated cell lysates (Supplementary Figure 1C). In this regard, all further experiments required siRNA treatment to be carried out, a minimum of, $72 \mathrm{~h}$ prior to drug treatment, thereby ensuring reducing MRP1 expression prior to drug administration. Figures 5B-D, depict the data obtained from MTT assays of commercial (U251), primary (MZ-18), and recurrent (MZ-256) GBM established cell lines. As can be seen in these figures, specific MRP1siRNA inhibition leads to a significant reduction in cell viability in all three GBM cell lines when combined with vincristine $(100 \mathrm{nM})$ or etoposide $(2 \mu \mathrm{M})$. There was no noted change in response to temozolomide $(150 \mu \mathrm{M})$ under these conditions, indicating that any effect noted previously in response to Reversan pre-treatment may be attributed to Pgp inhibition and not MRP1 targeting. Notably, all statistical analysis of control vs. treatment; or single vs. combination treatment groups is represented in Supplementary Table 2.

\section{Assessment of Alternative Role of MRP1 Inhibition in GBM}

Based on previous findings in neuroblastoma cells (Burkhart et al., 2009; Henderson et al., 2011), the effect of MK571 and Reversan treatment of GBM cells was assessed in vitro. As depicted in Figures 6A,C,E, there was no alteration in cell proliferation rates between controls and treated commercial, 


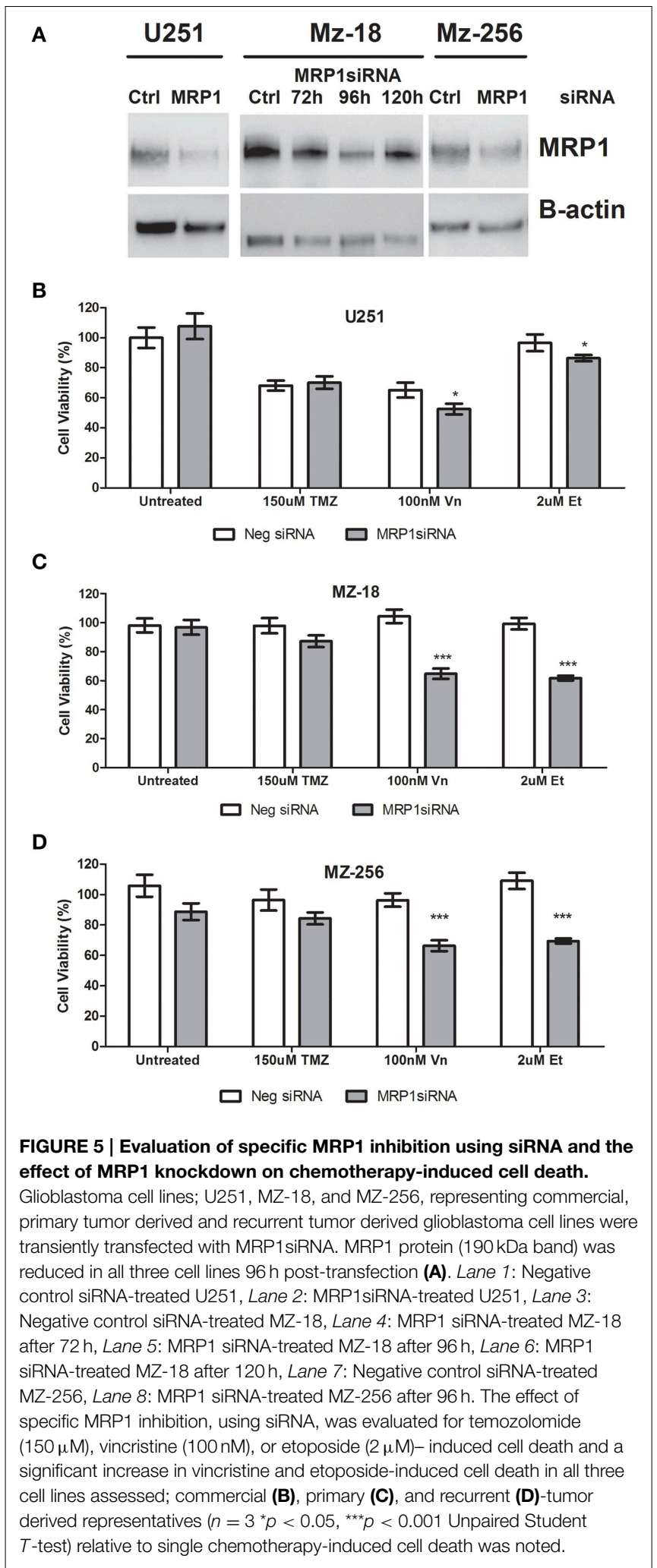

primary or recurrent GBM tumor derived lines over a $72 \mathrm{~h}$ period. Additionally, as reduced cell motility was noted in neuroblastoma cells after exposure to Reversan and with
MRP1siRNA transfection (Henderson et al., 2011), a 2Dmigration or wound closure assay, was carried out $7 \mathrm{~h}$ after pretreatment of the cells with this small molecule inhibitor $(15 \mu \mathrm{M}$, Figures 6B,D,F). In the case of glioblastoma cells however, Reversan treatment did not lead to any change in wound closure abilities in commercial, primary or recurrent GBM cell lines.

\section{Discussion}

Glioblastoma multiforme is the most aggressive form of brain cancer with a current median survival post-diagnosis of 14.6 months when treated. The Stupp protocol involves surgery and concurrent Temozolomide administration with radiotherapy (Stupp et al., 2005). A major challenge in terms of effective treatment of brain tumors is penetration of the blood brain barrier (BBB), a highly selective permeability barrier that separates the circulating blood from the brain extracellular fluid in the central nervous system (CNS). The physiology of this barrier is highly researched in an attempt to provide a means of ensuring active drug transport and efficient drug delivery to target regions of the brain. The role of MRP1, along with other membrane transporters including Pgp, in BBB function includes the efflux of cytotoxic hydrophobic drugs (Regina et al., 1998). In addition, the fact that MRP1 has been shown to be highly expressed in high grade glioma patient samples (Benyahia et al., 2004), with localization of MRP1 to the luminal side of brain capillary endothelial cells (Nies et al., 2004) suggests that the efficient efflux action of MRP1 in the GBM tumor microenvironment may contribute to the highly resistant nature of GBM tumors to current chemotherapeutics. This makes inhibition of MRP1 an attractive approach to improve drug influx to both GBM tumor brain regions and within brain tumor cells.

This study was carried out on a collection of both primary and recurrent patient-derived GBM tumor biopsy cell lines in addition to the commercially available U251 and A172 lines with the aim of identifying the true potential which MRP1 inhibition may play in primary or recurrent GBM tumor treatment. Of initial interest was the expression levels of MRP1 protein in the panel of GBM lines intended for in vitro study and also patient-derived tumor lysates from primary and recurrent glioblastoma. As a point of interest, a single oligoastrocytoma and two gliosarcoma patient tumor-derived lysates were also included in Western blotting analysis. Notably, the variable expression noted between individual samples (Figure 1), despite commonality in tumour stage, in addition to the varied genetic characteristics of each patient tumor sample (Supplemental Table 1) highlights the heterogeneity of this disease and the need for a more personalized and direct treatment approach as opposed to the pan cellular treatment currently employed through use of chemotherapy.

In addition to evaluating the effects of reduced MRP1 expression on drug resistance in GBM cells, the possibility of MRP1 playing an alternative role in GBM tumor formation was also evaluated. Previous findings in neuroblastoma cells (Burkhart et al., 2009; Henderson et al., 2011) showed that Reversan was capable of reducing cell motility and colony 


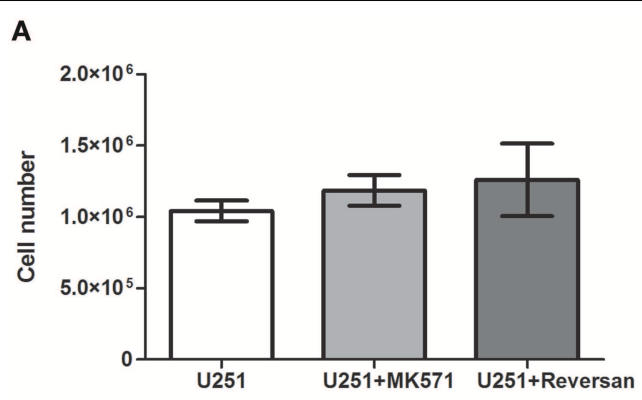

B
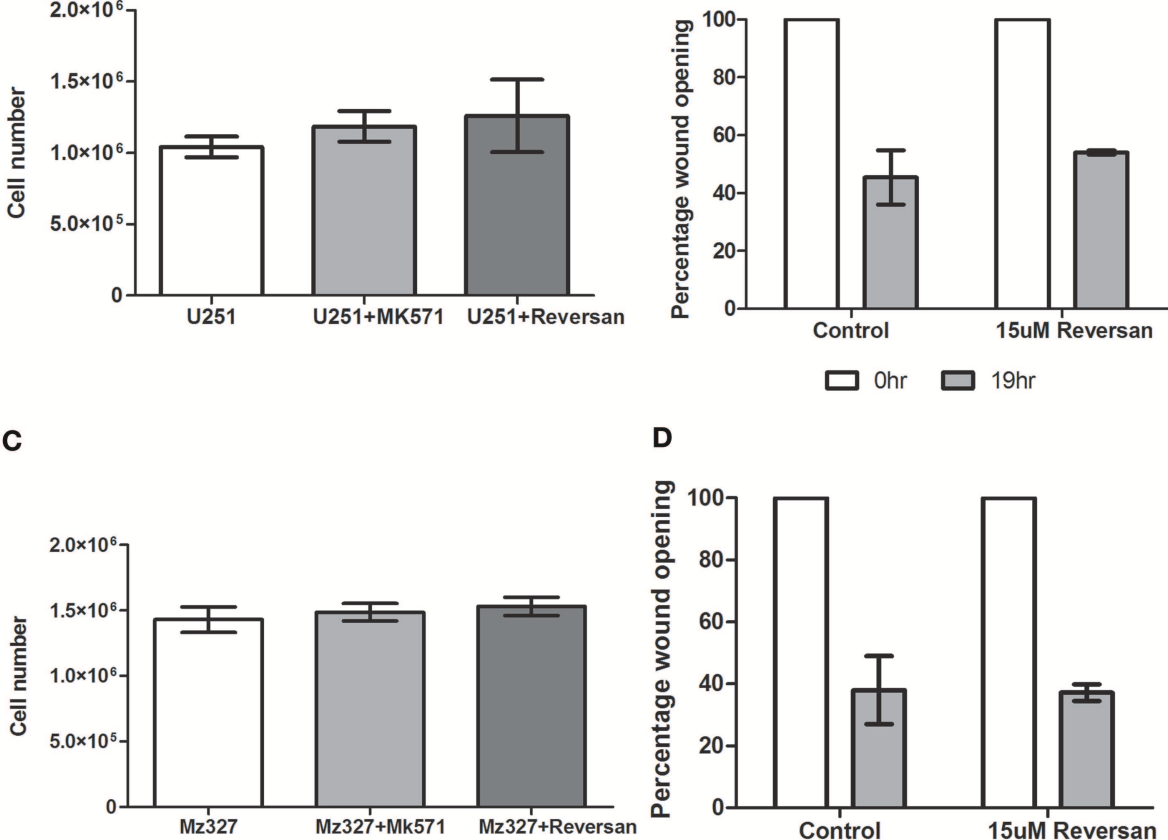

D

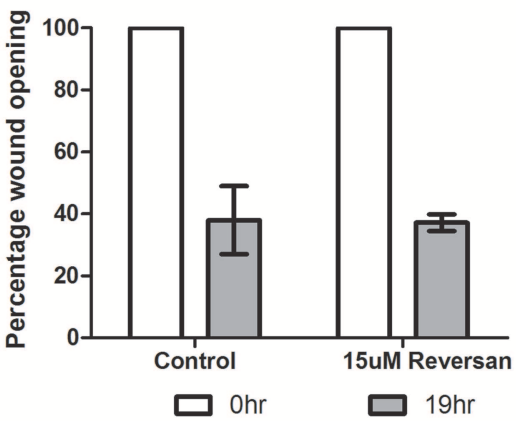

E

F
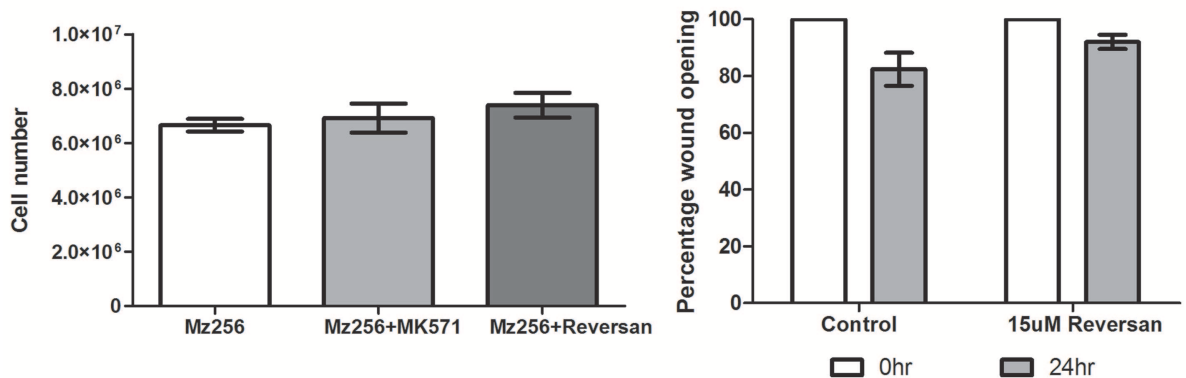

FIGURE 6 | The effect of MK571 and Reversan on cell proliferation and 2D-migration in commercial, primary, and recurrent GBM cell lines. Glioblastoma cells U251 (A), MZ-327 (C), and MZ-256 (E) were pre-incubated with non-specific MRP1 small molecule inhibitors MK571 (25 $\mathrm{M})$ or Reversan $(15 \mu \mathrm{M})$ and proliferation and wound-closure capabilities assessed. No significant change in proliferation was noted in any of the representative cell lines assessed. Similarly, treatment of glioblastoma cell lines with Reversan does not alter cell motility in commercial (B), primary (D) and recurrent (F) GBM cells. formation devoid of any effect on proliferation rates. In this regard, we assessed whether non-specific MRP1 inhibition by Reversan and/or MK571 led to any alteration in wound closure or proliferation rates in glioblastoma cells. Unlike the case for neuroblastoma, MRP1 inhibition in this study did not appear to play any role in cell migration or growth, independent of its role in drug resistance in GBM cells.

The most notable, and clinically relevant, finding presented in this publication, through the use of the MRP1 and MRP4 small molecule inhibitor, MK571, and also an MRP1 specific siRNA, is that MRP1 inhibition enhanced Vincristine- and Etoposide-, but not Temozolomide-induced cell death in primary or recurrent GBM cell lines. Inhibition of MRP1 and Pgp, using Reversan $(15 \mu \mathrm{M})$, and subsequent treatment with temozolomide
$(150 \mu \mathrm{M})$ however led to a statistically significant increase in cell death compared to temozolomide treatment alone across all primary, recurrent and commercial cell lines assessed in this study. In 2013, Veringa et al. (2013) detailed a list of substrate specificity for classical therapeutics for a range of efflux transporters, including MRP1 and Pgp. In their findings they list that temozolomide is a substrate for Pgp and Breast cancer related protein (BCRP) but not MRP1. Additionally, our findings corroborate Peignan et al. (2011), who note a lack of effect on cell death in the commercial GBM line T98G when MRP1 siRNA was used in vitro.

Vincristine and etoposide are two additional chemotherapies which are currently used in recurrent GBM treatment regimens as a means of palliative care, therefore the clinical application 
of assessing their improved efficacy was of great interest in both primary and recurrent GBM cell lines. MRP1 inhibition using MK571, Reversan and MRP1siRNA led to a significant enhancement in the cell death capabilities of both vincristine $(100 \mathrm{nM})$ and etoposide $(2 \mu \mathrm{M})$. In terms of MK571 use, neither etoposide nor vincristine are MRP4 substrates (Dallas et al., 2004), however both are known to be MRP1 substrates (Veringa et al., 2013). This, in addition to the use of an MRP1-specific siRNA devoid of off-target effects proves that the specific inhibition of the MRP1 transporter protein allows both vincristine $(100 \mathrm{nM})$ and etoposide $(2 \mu \mathrm{M})$ to induce cell death more effectively in GBM cells in vitro.

The findings of this study have significant implications in terms of providing researchers an opportunity to improve currently used chemotherapeutics for the initial treatment of primary GBM, and improved treatment for recurrent GBM patients. Additionally, the data obtained during this study is highly significant for further in vivo assessment of GBM orthotopic murine models of chemoresistance.

\section{References}

Abe, T., Hasegawa, S., Taniguchi, K., Yokomizo, A., Kuwano, T., Ono, M., et al. (1994). Possible involvement of multidrug-resistance-associated protein (MRP) gene expression in spontaneous drug resistance to vincristine, etoposide and adriamycin in human glioma cells. Int. J. Cancer 58, 860-864. doi: 10.1002/ijc.2910580619

Benyahia, B., Huguet, S., Decleves, X., Mokhtari, K., Criniere, E., Bernaudin, J. F., et al. (2004). Multidrug resistance-associated protein MRP1 expression in human gliomas: chemosensitization to vincristine and etoposide by indomethacin in human glioma cell lines overexpressing MRP1. J. Neurooncol. 66, 65-70. doi: 10.1023/B:NEON.0000013484.73208.a4

Bota, D. A., Desjardins, A., Quinn, J. A., Affronti, M. L., and Friedman, H. S. (2007). Interstitial chemotherapy with biodegradable BCNU (Gliadel) wafers in the treatment of malignant gliomas. Ther. Clin. Risk Manag. 3, 707-715.

Brada, M., Stenning, S., Gabe, R., Thompson, L. C., Levy, D., Rampling, R., et al. (2010). Temozolomide versus procarbazine, lomustine, and vincristine in recurrent high-grade glioma. J. Clin. Oncol. 28, 4601-4608. doi: 10.1200/JCO.2009.27.1932

Burkhart, C. A., Watt, F., Murray, J., Pajic, M., Prokvolit, A., Xue, C., et al. (2009). Small-molecule multidrug resistance-associated protein 1 inhibitor reversan increases the therapeutic index of chemotherapy in mouse models of neuroblastoma. Cancer Res. 69, 6573-6580. doi: 10.1158/0008-5472.CAN-0 9-1075

Calatozzolo, C., Gelati, M., Ciusani, E., Sciacca, F. L., Pollo, B., Cajola, L., et al. (2005). Expression of drug resistance proteins Pgp, MRP1, MRP3, MRP5 and GST-pi in human glioma. J. Neurooncol. 74, 113-121. doi: 10.1007/s11060-0046152-7

Campbell, M., Kiang, A. S., Kenna, P. F., Kerskens, C., Blau, C., O’Dwyer, L., et al. (2008). RNAi-mediated reversible opening of the blood-brain barrier. J. Gen. Med. 10, 930-947. doi: 10.1002/jgm.1211

Dallas, S., Schlichter, L., and Bendayan, R. (2004). Multidrug resistance protein (MRP) 4- and MRP 5-mediated efflux of 9-(2phosphonylmethoxyethyl)adenine by microglia. J. Pharmacol. Exp. Ther. 309, 1221-1229. doi: 10.1124/jpet.103.063966

Giannini, C., Sarkaria, J. N., Saito, A., Uhm, J. H., Galanis, E., Carlson, B. L., et al. (2005). Patient tumor EGFR and PDGFRA gene amplifications retained in an invasive intracranial xenograft model of glioblastoma multiforme. Neuro Oncol. 7, 164-176. doi: 10.1215/S1152851704000821

Henderson, M. J., Haber, M., Porro, A., Munoz, M. A., Iraci, N., Xue, C., et al. (2011). ABCC multidrug transporters in childhood neuroblastoma: clinical and

\section{Funding}

This work is funded by the Irish Cancer Society Research Fellowship CRF13TIV, awarded to AT, supported by Tesco Charity of the Year.

\section{Acknowledgments}

The authors would like to acknowledge Dr. Jamie I. Fletcher and Ms. Claudia Flemming (Children's Cancer Institute Australia, Lowy Cancer Research Centre, Randwick, NSW, Australia) for their assistance and advice regarding MRP1 (ABCC1) Western Blotting.

\section{Supplementary Material}

The Supplementary Material for this article can be found online at: http://journal.frontiersin.org/article/10.3389/fnins. 2015.00218/abstract

biological effects independent of cytotoxic drug efflux. J. Natl. Cancer Inst. 103, 1236-1251. doi: 10.1093/jnci/djr256

Hetschko, H., Voss, V., Horn, S., Seifert, V., Prehn, J. H., and Kogel, D. (2008). Pharmacological inhibition of Bcl-2 family members reactivates TRAILinduced apoptosis in malignant glioma. J. Neurooncol. 86, 265-272. doi: 10.1007/s11060-007-9472-6

Loscher, W., and Potschka, H. (2005a). Blood-brain barrier active efflux transporters: ATP-binding cassette gene family. NeuroRx 2, 86-98. doi: 10.1602/neurorx.2.1.86

Loscher, W., and Potschka, H. (2005b). Drug resistance in brain diseases and the role of drug efflux transporters. Nat. Rev. Neurosci. 6, 591-602. doi: $10.1038 / \mathrm{nrn} 1728$

Loscher, W., and Potschka, H. (2005c). Role of drug efflux transporters in the brain for drug disposition and treatment of brain diseases. Prog. Neurobiol. 76, 22-76. doi: 10.1016/j.pneurobio.2005.04.006

Murphy, A. C., Weyhenmeyer, B., Noonan, J., Kilbride, S. M., Schimansky, S., Loh, K. P., et al. (2014). Modulation of Mcl-1 sensitizes glioblastoma to TRAILinduced apoptosis. Apoptosis 19, 629-642. doi: 10.1007/s10495-013-0935-2

Nies, A. T., Jedlitschky, G., Konig, J., Herold-Mende, C., Steiner, H. H., Schmitt, H. P., et al. (2004). Expression and immunolocalization of the multidrug resistance proteins, MRP1-MRP6 (ABCC1-ABCC6), in human brain. Neuroscience 129, 349-360. doi: 10.1016/j.neuroscience.2004.07.051

Peignan, L., Garrido, W., Segura, R., Melo, R., Rojas, D., Carcamo, J. G., et al. (2011). Combined use of anticancer drugs and an inhibitor of multiple drug resistance-associated protein-1 increases sensitivity and decreases survival of glioblastoma multiforme cells in vitro. Neurochem. Res. 36, 1397-1406. doi: 10.1007/s11064-011-0464-8

Regina, A., Koman, A., Piciotti, M., El Hafny, B., Center, M. S., Bergmann, R., et al. (1998). Mrp1 multidrug resistance-associated protein and P-glycoprotein expression in rat brain microvessel endothelial cells. J. Neurochem. 71, 705-715. doi: 10.1046/j.1471-4159.1998.71020705.x

Reid, G., Wielinga, P., Zelcer, N., van Der Heijden, I., Kuil, A., De Haas, M., et al. (2003). The human multidrug resistance protein MRP4 functions as a prostaglandin efflux transporter and is inhibited by nonsteroidal antiinflammatory drugs. Proc. Natl. Acad. Sci. U.S.A. 100, 9244-9249. doi: 10.1073/pnas.1033060100

Sarkaria, J. N., Carlson, B. L., Schroeder, M. A., Grogan, P., Brown, P. D., Giannini, C., et al. (2006). Use of an orthotopic xenograft model for assessing the effect of epidermal growth factor receptor amplification on glioblastoma radiation response. Clin. Cancer Res. 12, 2264-2271. doi: 10.1158/1078-0432.CCR-0 $5-2510$ 
Sarkaria, J. N., Kitange, G. J., James, C. D., Plummer, R., Calvert, H., Weller, M., et al. (2008). Mechanisms of chemoresistance to alkylating agents in malignant glioma. Clin. Cancer Res. 14, 2900-2908. doi: 10.1158/1078-0432.CCR-07-1719

Sarkaria, J. N., Yang, L., Grogan, P. T., Kitange, G. J., Carlson, B. L., Schroeder, M. A., et al. (2007). Identification of molecular characteristics correlated with glioblastoma sensitivity to EGFR kinase inhibition through use of an intracranial xenograft test panel. Mol. Cancer Ther. 6, 1167-1174. doi: 10.1158/1535-7163.MCT-06-0691

Stupp, R., Hegi, M. E., Mason, W. P., Van Den Bent, M. J., Taphoorn, M. J., Janzer, R. C., et al. (2009). Effects of radiotherapy with concomitant and adjuvant temozolomide versus radiotherapy alone on survival in glioblastoma in a randomised phase III study: 5-year analysis of the EORTC-NCIC trial. Lancet Oncol. 10, 459-466. doi: 10.1016/S1470-2045(09)70025-7

Stupp, R., Mason, W. P., Van Den Bent, M. J., Weller, M., Fisher, B., Taphoorn, M. J., et al. (2005). Radiotherapy plus concomitant and adjuvant temozolomide for glioblastoma. N. Engl. J. Med. 352, 987-996. doi: 10.1056/NEJMoa043330

Stupp, R., Tonn, J. C., Brada, M., Pentheroudakis, G., and Group, E. G. W. (2010). High-grade malignant glioma: ESMO Clinical Practice Guidelines for diagnosis, treatment and follow-up. Ann. Oncol. 21(Suppl 5), v190-v193. doi: 10.1093/annonc/mdq187
Veringa, S. J., Biesmans, D., Van Vuurden, D. G., Jansen, M. H., Wedekind, L. E., Horsman, I., et al. (2013). In vitro drug response and efflux transporters associated with drug resistance in pediatric high grade glioma and diffuse intrinsic pontine glioma. PLoS ONE 8:e61512. doi: 10.1371/journal.pone.0061512

WHO and IARC. (2008). Globocan Cancer Incidence and Mortality Worldwide in 2008 [Online]. Available online at: http://globocan.iarc.fr/ (Accessed 29 December, 2014)

Conflict of Interest Statement: The authors declare that the research was conducted in the absence of any commercial or financial relationships that could be construed as a potential conflict of interest.

Copyright (c) 2015 Tivnan, Zakaria, O’Leary, Kögel, Pokorny, Sarkaria and Prehn. This is an open-access article distributed under the terms of the Creative Commons Attribution License (CC BY). The use, distribution or reproduction in other forums is permitted, provided the original author(s) or licensor are credited and that the original publication in this journal is cited, in accordance with accepted academic practice. No use, distribution or reproduction is permitted which does not comply with these terms. 